The work of N. O'Connor and J. Tizard ${ }^{1}$ at Darenth Park suggested that there were large numbers of people detained in mental deficiency hospitals who could in the changed postwar economic climate be earning their living in open competition-and sometimes earning more than the nurses employed to look after them. Their findings have been supported by others, ${ }^{2}$ and recent surveys ${ }^{3}$ suggest that there are still in hospitals for the mentally subnormal considerable numbers of people who in respect of intelligence alone have sufficient ability to maintain themselves in the general community. In regard to the more severely mentally handicapped, however, Tizard and J. C. Grad 4 found that two-thirds of idiots and imbeciles in hospital had a major additional disability.

It has been suggested recently ${ }^{5}$ that a considerable proportion of mentally retarded patients at present in hospital need not be there, and that they should be transferred to local authority care. But this carries the implication that staff would still need to be employed to look after them. And indeed one reason why many very mentally handicapped patients need a hospital type of care is the presence of multiple handicap and the need for physical nursing.

A report ${ }^{6}$ recently issued by the Royal College of Nursing lays stress on the role of the nurse in meeting the educational and social needs of the mentally subnormal. The report claims that with the gradual introduction of specialized staff into the team the nurse has tended to lose the opportunity to organize a therapeutic regimen. In 1965 some 10,000 nurses were employed in this work whole-time and about 3,300 part-time in England and Wales. ${ }^{7}$ Half the full-time men and a quarter of the full-time women are trained nurses. The Royal College inquiry showed there were also 1,844 student nurses in this branch in England and Wales, with $98 \%$ from the U.K. and Eire in the North and $35 \%$ in the South-east. The report calls for improvement in the status and training of the nurse in this branch of the profession and rejects-though perhaps questionably-an amalgamation of the training of these nurses with that of nurses for mental illness. Tizard ${ }^{8}$ has suggested alternative forms of provision for those mentally retarded patients who need residential care. But there will for long be a continuing need for a body of dedicated men and women to care for the mentally handicapped. Moreover, there should be a further review of the professional training open to them.

\section{Hypermobile Joints}

Generalized laxity of articular ligaments is a feature of such inherited diseases of connective tissue as Marfan's syndrome, the Ehlers-Danlos syndrome, and osteogenesis imperfecta. ${ }^{1}$ It is also seen in rare metabolic conditions such as homocystinuria $^{2}$ and hyperlysinaemia. ${ }^{3}$ Acquired hypermobility may follow inflammatory polyarthritis, including rheumatoid arthritis, and it is a characteristic and prominent abnormality in neuropathic joint disease. Joints which are unduly lax may be injured by minor degrees of trauma which would be harmless to joints of normal stability, and are therefore liable to develop traumatic synovitis, with serous or haemorrhagic effusions and later secondary osteoarthrosis.

Generalized laxity of joints also occurs as an isolated finding in otherwise normal people, often with a familial incidence. ${ }^{s}$ Thus in a study of 435 adult orthopaedic outpatients it was found that $4 \%$ showed hypermobility of three or more pairs of joints. ${ }^{\circ}$ Again, C. Carter and J. Wilkinson found hypermobility of four or more pairs of joints in $7 \%$ of 285 schoolchildren.' Joint laxity of this type predisposes to dislocation and deformity of the hip, patella, shoulder, and other joints. ${ }^{8-10}$

Recently J. A. Kirk, B. M. Ansell, and E. G. L. Bywaters ${ }^{11}$ re-examined 24 patients whose musculoskeletal complaints had originally been attributed by various examining physicians to generalized joint laxity. In three-quarters of these patients symptoms had begun before the age of 15 ; the sex incidence was equal in the children, but all the adults were femalepossibly by chance. The main complaints were of joint pain and effusion, most often in the knees. Though symptoms predominated in joints of the lower limbs, hypermobility was most easily detected in movements of the hands and wrists. One-third of the patients considered themselves to be "double-jointed."

The clinical picture in these cases was very variable, ranging from children with relatively transient pain in muscles or joints to adults with long-standing pain and effusion in the joints leading to early degenerative arthritis. The patients were carefully examined for signs of hereditary disorders of connective tissue, such as hyperelastic skin, easy bruising, high palate, or abnormalities of body proportion. Such examination was essentially negative, nor was there any evidence of inflammatory synovitis: the sedimentation rate was normal, and needle biopsy of a joint carried out on one patient showed normal synovium. Nine first-degree relatives of these patients were also examined and were found to show evidence of joint hypermobility, two of them having symptoms attributable to it.

The question arises whether the condition represents one extreme of a normal variation in joint mobility, or whether it is to be regarded as an incomplete form of such disorders as the Marfan or the Ehlers-Danlos syndromes. Since we lack any firm biochemical criteria for the diagnosis of these diseases it is not yet possible to be certain on this point, but the absence of any other stigmata among patients or their relatives is against the second view. Normal people vary widely with respect to joint mobility, ${ }^{12}$ and it seems unlikely that there is anything more than a quantitative distinction to be drawn between normal persons and patients who develop symptoms from their hypermobile joints.

The importance of this syndrome lies in its recognition. It is not uncommon to find that such patients have had numerous but uncertain diagnoses attached to their complaint, and they are consequently relieved to receive a confident explanation of their problem. Management is largely confined to avoidance of any activity which brings on symptoms in the joints, together with general exercises, such as swimming, directed towards developing musculature. Though little else can be offered by way of treatment, it is at least reassuring for the patient to know that the condition does not carry the serious prognosis which may apply to some other forms of joint disease.

\footnotetext{
McKusick, V. A., Heritable Disorders of Connective Tissue, 1966, 3rd ed. St. Louis.

Schimke, R. N., McKusick V. A., Huang, T., and Pollack, A. D., J. Amer. med. Ass., 1965, 193, 711 .

Ghadimi, H., Binnington, V. I., and Pecora, P., New Engl. 7. Med., $1965,273,723$.

Key, J. A., 7. Awer med Ass., 1927, 88, 1710.

Sturkie, P. D. F. Hereu., 1941, 32, 232

- Sutro, C. J., Surgcrv, 1947, 21, 67.

' Carter, C. and Wilkinson, J.. F. Bone ft Surg., 1964, 46B, 40.

- Massie, W. K and Howorth. M B., J. Bone of Surz., 1951, 33A, 190.

9 Hass, J., and Hass, R., \%. Bons it Surg., 1958, 40A, 663.

- Carter, C., and Sweetnam. R.. F. Bone it Surg., 1960, 42B, 721.

1 Kirk. J. A., Ansell, B. M., and Bywaters, E. G. L., Ann. rheum. Dis., $1967,26,419$.

Scott, J. T., Ann. rheum. Dis., 1960, 19, 361.
} 